RESEARCH

\title{
Implantation failure in rats with subclinical hypothyroidism is associated with LIF/STAT3 signaling
}

\author{
Ling Shan ${ }^{1,2}$, Yingying Zhou' ${ }^{1}$, Shiqiao Peng ${ }^{1}$, Xinyi Wang ${ }^{1,3}$, Zhongyan Shan ${ }^{1}$ and Weiping Teng ${ }^{1}$ \\ ${ }^{1}$ Department of Endocrinology and Metabolism, Institute of Endocrinology, Liaoning Provincial Key Laboratory of Endocrine Diseases, The First Hospital \\ of China Medical University, Shenyang, People's Republic of China \\ ${ }^{2}$ Department of Endocrinology and Metabolism, People's Hospital of Liaoning Province, Shenyang, People's Republic of China \\ ${ }^{3}$ Department of Laboratory Medical, The First Hospital of China Medical University, Shenyang, People's Republic of China \\ Correspondence should be addressed to Z Shan: shanzhongyan@medmail.com.cn
}

\begin{abstract}
Background: Pregnant women with subclinical hypothyroidism are associated with an increased risk of spontaneous abortion. This study aims to investigate the mechanisms underlying the effects of maternal subclinical hypothyroidism during early pregnancy on abortion in the uterus, focusing upon the LIF/STAT3 signaling pathway.

Methods: One hundred five Wistar rats were randomly divided into three groups (35 rats in each group): control (CON) group, subclinical hypothyroidism $(\mathrm{SCH})$ group and overt hypothyroidism $(\mathrm{OH})$ group. We examined the weight of rat uteri, rat placenta and embryos. We also determined the number of implantation sites and the embryo absorption rates. The protein and mRNA expressions of TSHR, TR- $\alpha$, TR- $\beta$, LIFR, gp130, JAK1, p-STAT3 and STAT3 were measured by immunohistochemical staining, real-time PCR and Western blotting.

Results: The weights of rat uteri, rat placenta and embryos were significantly reduced in the $\mathrm{SCH}$ and $\mathrm{OH}$ groups. The number of implantation sites was significantly decreased in the $\mathrm{SCH}$ and $\mathrm{OH}$ groups, while embryo absorption rates were significantly increased. The mRNA and protein expressions of TSHR were upregulated in the $\mathrm{SCH}$ and $\mathrm{OH}$ groups, while TR- $\alpha$ and TR- $\beta$ showed no difference when compared between the three groups. The expression levels of LIFR, gp130, JAK1 and p-STAT3 were significantly higher in the $\mathrm{SCH}$ and $\mathrm{OH}$ groups.

Conclusions: Clinical and subclinical hypothyroidism during early pregnancy might cause adverse pregnancy outcomes. Implantation failure in rats with subclinical hypothyroidism was associated with abnormal LIF/STAT3 signaling.
\end{abstract}

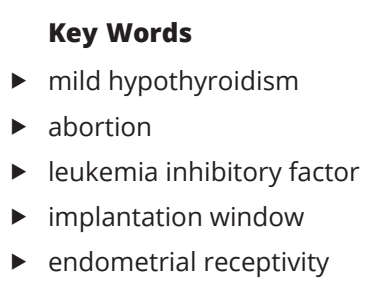

\section{Key Words}

- mild hypothyroidism

- abortion

- leukemia inhibitory factor

- implantation window

- endometrial receptivity

\section{Introduction}

Subclinical hypothyroidism (SCH), characterized by elevated levels of thyroid-stimulating hormone (TSH) with total thyroxine (TT4) within the normal reference range, is the most common type of thyroid disorder in pregnancy (1). A previous large cohort study in America used trimester-specific references to classify the definition of hypothyroidism in pregnancy and found that $15.5 \%$ of pregnant women had increased TSH during pregnancy, of which $2.4 \%$ were overt hypothyroidism $(\mathrm{OH})$ and $97.6 \%$ were SCH (2).

Clinical studies have shown that pregnant women with $\mathrm{OH}$ or $\mathrm{SCH}$ are likely to have an increased risk of
Endocrine Connections (2019) 8, 718-727 
pregnancy complications such as spontaneous abortion. Although SCH leads to a lower incidence of pregnancy complication compared to $\mathrm{OH}$, the risk of spontaneous abortion still increases with the prevalence of $\mathrm{SCH}(3,4)$. Negro et al. demonstrated that women with TSH levels between 2.5 and $5.0 \mathrm{mIU} / \mathrm{L}$ in the first trimester and those who are negative to thyroid antibody are associated with a higher rate of spontaneous pregnancy loss as compared with women with TSH levels lower than $2.5 \mathrm{mIU} / \mathrm{L}$ (5). However, the mechanisms underlying miscarriage caused by SCH are still unclear.

Leukemia inhibitory factor (LIF) is known to play a vital role in the progression of blastocysts to implantation. In humans, LIF regulates the receptivity of the uterus by controlling blastocyst implantation via the promotion of proliferation and differentiation (6). LIF can also regulate extravillous trophoblast (EVT) invasion by inducing the phosphorylation of STAT3 and plays an important role in the implantation of the embryo into the endometrium (7).

For rats, successful implantation only occurs during a short limiting period generally from 4 to 6 days of pregnancy (8). During 12 to 14 days, the occurrence of abortion (in our previous experiments) can be clearly observed. In this study, we used a model of rats with $\mathrm{SCH}$ during pregnancy and observed the implantation site and abortion rate on day 5 and day 13 of pregnancy respectively, focusing particularly on the LIF/STAT3 signaling pathway.

\section{Materials and methods}

\section{Animals}

One hundred five nulliparous female Wistar rats, weighing 180-200g (virgin 6-7 weeks old), were maintained on a 12:12-h light/darkness cycle and fed normal rat chow ad libitum. All animals and experimental procedures were approved by the Animal Care and Use Committee at China Medical University, which complied with the National Institute of Health Guide for the Care and Use of Laboratory Animals. The rats were randomly assigned to three groups: control group (CON, $n=35$ ), $\mathrm{OH}$ group $(n=35)$ and SCH group $(n=35)$. The rats were treated by intraperitoneal (i.p.) injection of 3\% pentobarbital sodium $(0.1 \mathrm{~mL} / 100 \mathrm{~g})$ and placed on an operating table. Rats in the $\mathrm{OH}$ and $\mathrm{SCH}$ groups were subjected to thyroidectomy, removal of the thyroid gland, to establish a hypothyroid model. Rats in the CON group were given a sham operation that did not involve removal of the thyroid gland, as described in a previous work (9). After surgery, rats were kept at $34 \pm 2^{\circ} \mathrm{C}$ under an electric blanket until they awoke. Four weeks after surgery, rats in the $\mathrm{SCH}$ group were injected subcutaneously with L-thyroxine (L-T4, Sigma) $1.0 \mu \mathrm{g} / 100 \mathrm{~g} /$ day on the back. Rats in the $\mathrm{CON}$ and $\mathrm{OH}$ groups were injected subcutaneously with physiological saline $(50 \mu \mathrm{L} / 100 \mathrm{~g} /$ day $)$ on the back. Calcium lactate $(0.1 \% \mathrm{w} / \mathrm{v})$ was added to the drinking water for all rats after surgery. After 9 days of injections, all rats were mated with normal male rats (male:female=1:2). The day of vaginal plus was confirmed by microscopic observation and designated as E0. We collected tissues on days E0, E5 and E13. We measured the weight of the uterus on days E0 and E5 and the weight of the placenta and embryos on day E13. We also calculated the number of implantation sites (Fig. 2A) and the absorptions (Fig. 2B). We used the ratio of number of absorptions and number of all the embryos (viable and absorbed) represented the absorption rate.

\section{Measurement of TT4 and TSH}

Blood samples obtained from all groups were immediately centrifuged at $13,000 \mathrm{~g}$ for $13 \mathrm{~min}$ and stored at $-80^{\circ} \mathrm{C}$ for subsequent measurement of TT4 and serum TSH using a supersensitive chemiluminescence immunoassay (Immulite). All samples were assayed in duplicate. The intra- and interassay coefficients of variation were below $10 \%$ and the sensitivity for TT 4 was $1 \mu \mathrm{g} / \mathrm{dL}$. The results below this limit of quantification were recorded at $1 \mu \mathrm{g} / \mathrm{dL}$ for statistical purposes.

\section{RNA isolation and quantitative real-time PCR}

RNA was extracted from rat uteri from each group using TRIzol (Life Tech). First strand of cDNA was synthesized using total RNA and RT-PCR was carried out by TaqMan expression assays, using glyceraldehyde-3phosphatedehydrogenase (GAPDH) as a control (R\&D Systems). The sequences for TSHR, TR- $\alpha 1$, TR- $\alpha 2$, TR- $\beta$, LIFR, Gp130, JAK1 and GAPDH were performed through the ABI PRISM system. Primer sequences are shown in Table 1 and were analyzed with BLAST software on NCBI. Reactions were performed in a total volume of $20 \mu \mathrm{L}$ and gene expression was determined by SYBR Premix Ex Taq TM II (TaKaRa Biotechnology Co., Ltd.) in accordance with the manufacturer's instructions. Reactions began with a $10 \mathrm{~s}$ hot activation of Taq polymerase at $95^{\circ} \mathrm{C}$, followed by $40-45$ cycles of amplification in three steps (denaturation at $95^{\circ} \mathrm{C}$ for $5 \mathrm{~s}, 30 \mathrm{~s}$ annealing at $60^{\circ} \mathrm{C}$ https://ec.bioscientifica.com https://doi.org/10.1530/EC-19-0185 (c) 2019 The authors Published by Bioscientifica Ltd
This work is licensed under a Creative Commons Attribution-NonCommercial 4.0 International License. ded from Bioscientifica.com at 04/26/2023 11:54:26AM 
Table 1 Primer sequences for the real-time PCR.

\begin{tabular}{|c|c|c|}
\hline Gene & Forward primer & Reverse primer \\
\hline Tshr & СССTGTCCCTCACTATCTGC & ACTGGTTCTCCTGCCTTCAG \\
\hline $\operatorname{Tr}-\alpha 1$ & CCACATGAAAGTCGAGTGCC & AAGAGATGGGGGTTCTCCCT \\
\hline$T r-\alpha 2$ & GGGGAAGGAGAAGGAGCAT & AGGGGTAGGAGGGTGGTCTT \\
\hline $\operatorname{Tr}-\beta$ & GGTGGCAAGGTTGATCTGGA & CACAGGGCAGCTCACAAAAC \\
\hline Lifr & CCCACGCAACACAGAATACA & GGTCAGGAGCCATTTTCAAG \\
\hline Gp130 & ACCACCACCACCACTTGACT & GTGCTTCCTCCACCAACATC \\
\hline Jak1 & GGAGGAGCAGAATCCAGACA & TCAACCTTCCCAAAGTGACC \\
\hline Gapdh & GACATGCCGCCTGGAGAAAC & AGCCCAGGATGCCCTTTAGT \\
\hline
\end{tabular}

and $30 \mathrm{~s}$ extension at $72^{\circ} \mathrm{C}$ ). The mRNA expression was measured as a ratio to GAPDH.

\section{Immunohistochemistry}

Immunohistochemical studies were conducted on uterine tissue. Samples were first embedded in paraffin and then sectioned at a thickness of $5 \mu \mathrm{m}$. Tissue samples were then dewaxed and incubated in $0.3 \% \mathrm{H}_{2} \mathrm{O}_{2}$ for $10 \mathrm{~min}$. For staining, slices were first treated with a heated antigen repair protocol in $0.03 \mathrm{M}$ citrate buffer ( $\mathrm{pH} 6.0$ ) for $40 \mathrm{~min}$ at $95^{\circ} \mathrm{C}$. All samples were then incubated in $5 \%$ bovine serum albumin for $20 \mathrm{~min}$ to block nonspecific binding sites after different types of antigen repair. All sections were incubated with rabbit polyclonal antibodies against TSHR (1:500), TR- $\alpha$ (1:100), TR- $\beta$ (1:300), STAT3 (1:200), and p-STAT3 (1:250). All antibodies were purchased from Abcam and were incubated with sections overnight at $4^{\circ} \mathrm{C}$. Slices were then stained with secondary antibody (Santa Cruz Biotechnology). Sections were then stained with DAB (Santa Cruz Biotechnology) and observed under microscope in order to develop positive antibody binding signals. The nuclei of sections were then counterstained with hematoxylin. Finally, sections were dehydrated, rinsed and mounted in neutral gum. All sections were then analyzed at a magnification of $\times 200$. Five visual fields per slide were randomly selected. The area integrated optical density (AIOD) of positive cells in each field was calculated using a Metamorph/DPIO/BX51 morphology image analysis system (Olympus) in order to assess the expression of each target. The results were analyzed using ImagePro Plus software (Bethesda, MD, USA).

\section{Western blotting}

Tissues were lysed in radioimmunoprecipitation (RIPA) buffer and total protein concentration was determined with a bicinchoninic acid (BCA) assay (Beyotime). Then, $20 \mu \mathrm{g}$ of total protein from each sample was separated by $10 \%$ SDS-PAGE and then transferred to PVDF membranes. Membranes were then washed, blocked and incubated sequentially with specific primary antibodies: rabbit polyclonal antibody LIF (1:1,000), LIFR (1:200); p-STAT3 (1:2,000), ER- $\alpha$ (1:1,000); gp130 (1:1,000); JAK1 $(1: 5,000)$ (Abcam) and mouse polyclonal anti-GAPDH (1:3,000; Santa Cruz Biotechnology). Incubation in primary antibodies was followed by incubation with goat anti-rabbit secondary antibody $(1: 5,000$, Santa Cruz Biotechnology). Positive antibody binding reactions were detected by an enhanced chemiluminescence using an ECL system and each experiment was performed in triplicate. The relative densitometry of the band was measured using ImageJ software (Bethesda).

\section{Statistical analysis}

The statistical data are presented as mean \pm S.D. SPSS20.0 (IBM) was used for all data analyses. The $t$-test was applied to assess the statistical significance of the differences between paired groups of data, and differences among more than two groups were analyzed using one-way ANOVA. $P<0.05$ was considered as statistically significant. All artwork was created by using GraphPad Prism (6.0).

\section{Results}

\section{TT4 and TSH levels in maternal rats}

To evaluate maternal thyroid function, blood samples from the $\mathrm{CON}, \mathrm{SCH}$ and $\mathrm{OH}$ groups were evaluated for serum levels of TT4 and TSH. Compared to the CON group, the $\mathrm{OH}$ group showed a significant increase in TSH and a reduction in TT4 (Table 2). Serum TSH in the $\mathrm{SCH}$ group was significantly higher than in the CON group $(P<0.05)$, but there was no significant difference in TT4 levels between these two groups. The $\mathrm{SCH}$ group also had a significantly higher serum level of TT4 than the $\mathrm{OH}$ group $(P<0.05)$. Collectively, normal TT4 and higher TSH levels confirmed the successful creation of a rat model of maternal SCH (Table 2). All maternal rats maintained stable levels of TT4 and TSH level when analyzed at E0, E5 and E13 (Table 2).

\section{Pregnancy outcomes}

On E0 and E5, we recorded the weight of rat uteri, it was much lower in the $\mathrm{SCH}$ and $\mathrm{OH}$ group compared to the control group $(P<0.05$; Fig. $1 \mathrm{~A}$ and $\mathrm{B})$. Furthermore, on E13, the weight of rat placenta and embryos were much lower in the $\mathrm{SCH}$ and $\mathrm{OH}$ groups $(P<0.05$; Fig. $1 \mathrm{C}$ and $\mathrm{D})$.

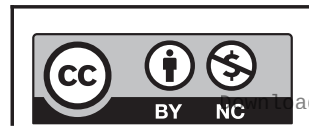



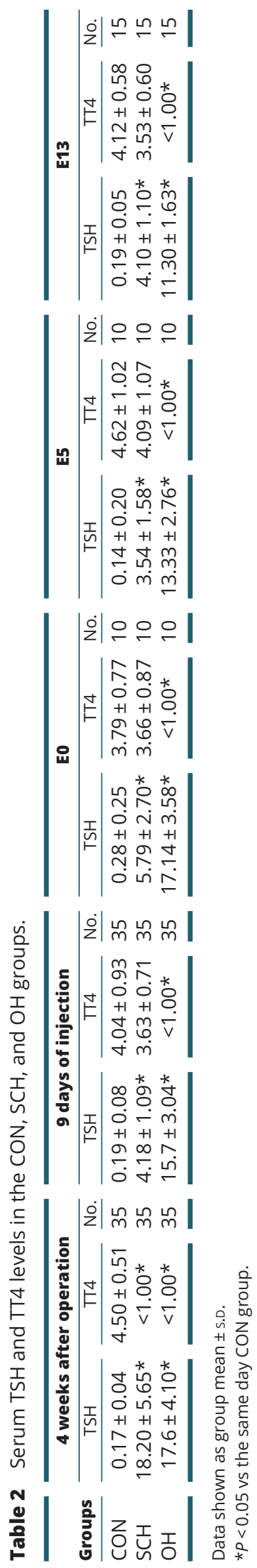

On E5, we observed and recorded the number of implantation sites in each group (Fig. 2A). We found that the number of implantation sites of $\mathrm{SCH}$ and $\mathrm{OH}$ group were lower than that in the CON group $(P<0.05$; Fig. $2 \mathrm{~B})$. The $\mathrm{OH}$ group was the lowest, but there was no significant difference between the $\mathrm{SCH}$ and $\mathrm{OH}$ groups (Fig. 2B).

On E13, we observed and recorded the number of absorptions in each group (Fig. 2C) and calculated the embryo absorption rates. We found that the embryo absorption rates were significantly higher in the $\mathrm{SCH}$ and $\mathrm{OH}$ groups $(P<0.05$; Fig. $2 \mathrm{D})$. The $\mathrm{OH}$ group was the highest, but there was no significant difference between the $\mathrm{SCH}$ and $\mathrm{OH}$ groups (Fig. 2D).

\section{Uterine TSHR, TR- $\alpha 1$, TR- $\alpha 2$ and TR- $\beta$ mRNA expressions}

We measured the mRNA expression levels of TSHR, TR- $\alpha 1$, TR- $\alpha 2$ and TR- $\beta$ in uterus of the three groups. On E0 and E5, the $\mathrm{SCH}$ and $\mathrm{OH}$ groups showed an increased expression of mRNA levels for TSHR compared with the CON group, with the $\mathrm{OH}$ group showing the most significant increase on E0 $(P<0.05$; Fig. $3 \mathrm{~A}$ and $\mathrm{E})$.

There was no significant difference between these groups in terms of the expression of mRNA levels for TR- $\alpha 1$ ( $P>0.05$; Fig. 3B and F), TR- $\alpha 2(P>0.05$; Fig. 3C and $\mathrm{G})$ and TR- $\beta(P>0.05$; Fig. 3D and H) on E0 and E5.

\section{Immunohistochemical staining of TSHR, TR- $\alpha$ and TR- $\beta$ in the uterus}

Immunohistochemical analysis detected expression of TSHR, TR- $\alpha$ and TR- $\beta$ on E0 and E5 (Figs $4 \mathrm{~A}$ and $5 \mathrm{~A}, \mathrm{C}$ ); AOID levels of TSHR in the SCH and $\mathrm{OH}$ groups were significantly higher than those in the CON group $(P<0.05$; Fig. 4B), although there was no significant difference in TR- $\alpha$ and TR- $\beta$ between the three groups $(P>0.05$; Fig. 5B and D).

\section{Uterine expression of LIFR, gp130 and JAK1 mRNA}

The mRNA levels of LIFR, gp130 and JAK1 were detected on E0 and E5 by real-time PCR. Data showed that on E0, the mRNA levels of these three targets were significantly higher in the $\mathrm{SCH}$ and $\mathrm{OH}$ groups than in the controls $(P<0.05$; Fig. 6A, C and E). There was no significant difference between the three groups on E5 $(P>0.05$; Fig. 6A, C and E).

Furthermore, from E0 to E5, these three indicators showed a general tendency to increase in the control

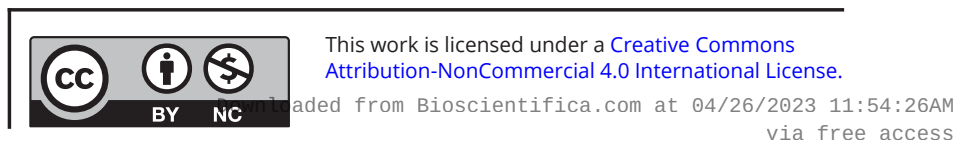



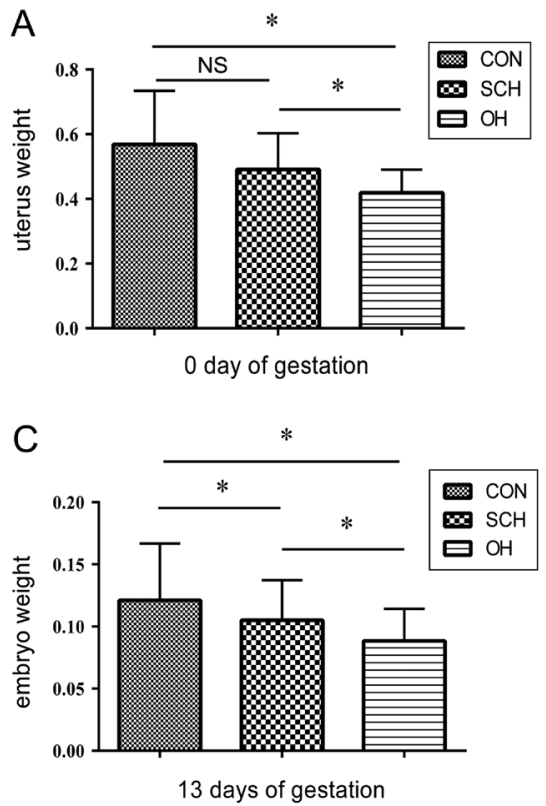
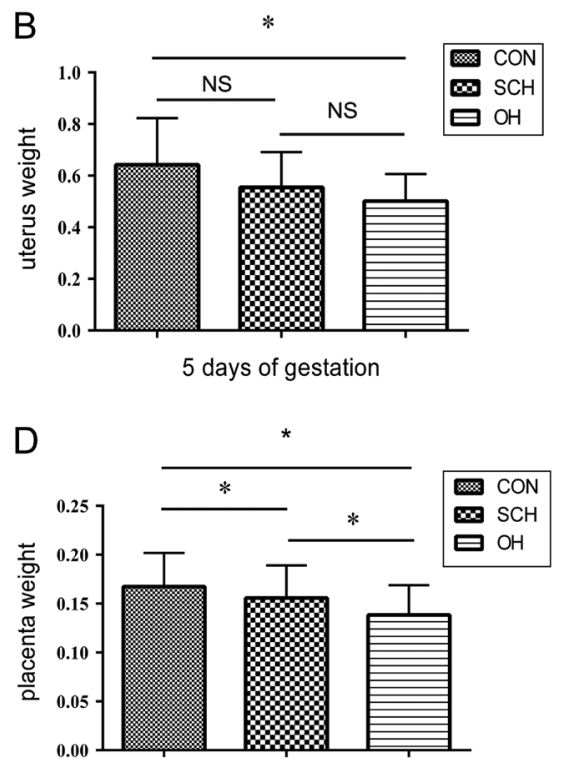

13 days of gestation

\section{Figure 1}

( $A$ and $B$ ) Uterine weight of pregnant rats from the $\mathrm{CON}, \mathrm{SCH}$ and $\mathrm{OH}$ groups at $\mathrm{O}$ and 5 days of gestation $\left({ }^{*} P<0.05\right)$. (C and D) Weight of embryos and placenta in pregnant rats from the $\mathrm{CON}, \mathrm{SCH}$ and $\mathrm{OH}$ groups at 13 days of gestation $(* P<0.05)$. NS, non-significant. group $(P<0.05$; Fig. 6B, D and $\mathrm{F}$ ), although no significant difference was detected in the $\mathrm{SCH}$ and $\mathrm{OH}$ groups $(P>0.05$; Fig. 6B, D and F).
From E0 to E5, these five proteins showed a general tendency to increase in the control group $(P<0.05$; Fig. 7B (ii), C (ii), D (ii), E (ii) and F (ii)).

\section{Levels of LIF, LIFR, gp130, JAK1 and p-STAT3 protein in} the uterus

The protein levels of LIF, LIFR, gp130, JAK1 and p-STAT3 were examined by Western blotting (Fig. 7A). Data showed that on $\mathrm{E} 0$, the protein levels in the $\mathrm{SCH}$ and $\mathrm{OH}$ groups were significantly higher than the controls $(P<0.05$; Fig. 7B (i), C (i), D (i), E (i) and F (i)) and that these five proteins showed no difference between the three groups on E5 (P>0.05; Fig. 7B (i), C (i), D (i), E (i) and F (i)).

\section{Discussion}

The interaction between embryo implantation and a receptive uterine environment is a vital aspect of successful embryo implantation (10, 11, 12). A range of cytokines and growth factors act as either autocrine and paracrine factors, with both temporal- and spatialspecificity, in order to regulate uterine receptivity (13, 14). Uterine implantation is classified into three phases:
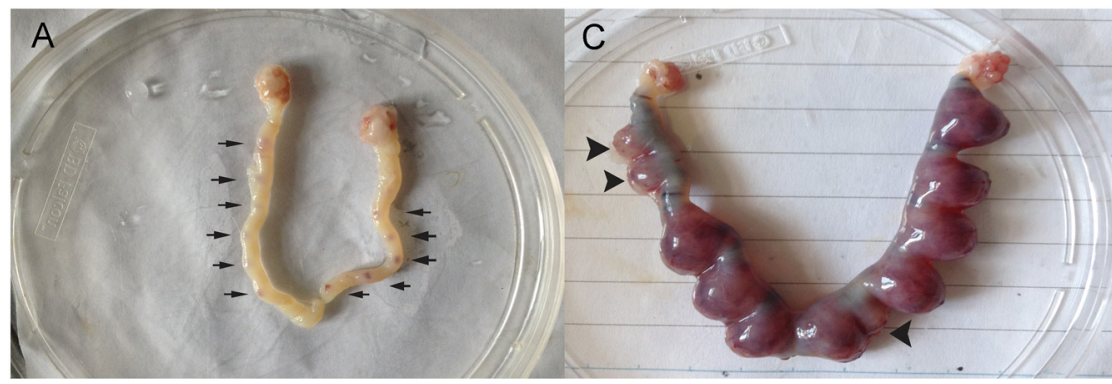

B

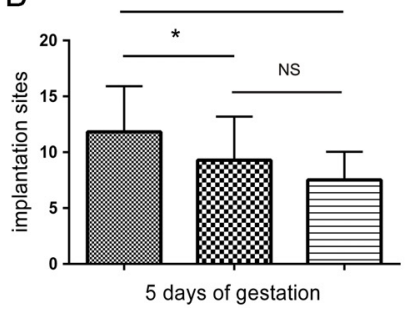

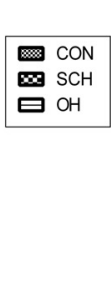

D

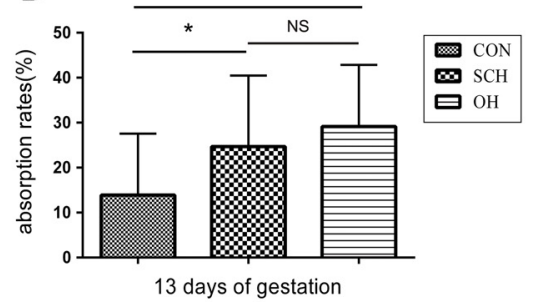

\section{Figure 2}

(A) The arrows point to the implantation sites of pregnant rats on 5 days of gestation. (B) Implantation sites of pregnant rats from the CON, $\mathrm{SCH}$ and $\mathrm{OH}$ groups at 5 days of gestation ( $\left.{ }^{*} P<0.05\right)$. (C) The arrows point to the embryos absorpted on 13 days of gestation. (D) Embryo absorption rates from the $\mathrm{CON}, \mathrm{SCH}$ and $\mathrm{OH}$ groups at 13 days of gestation $(* P<0.05)$. NS non-significant. https://ec.bioscientifica.com https://doi.org/10.1530/EC-19-0185 (c) 2019 The authors Published by Bioscientifica Ltd
This work is licensed under a Creative Commons Attribution-NonCommercial 4.0 International License. ded from Bioscientifica.com at 04/26/2023 11:54:26AM via free access 
A

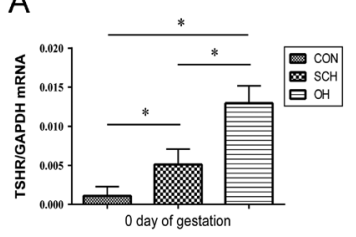

E

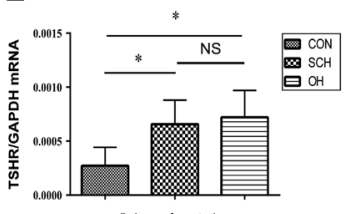

B

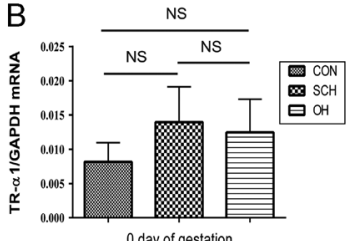

F

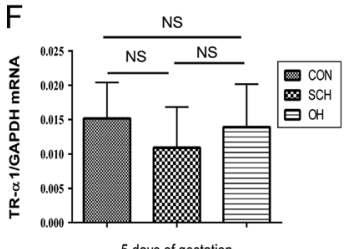

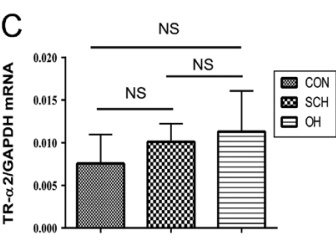

0 day of gestation

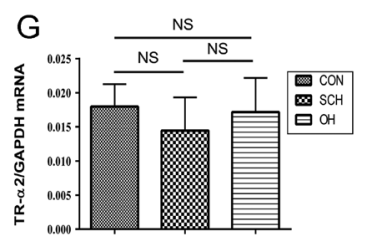

5 days of gestation

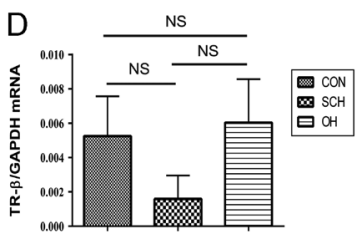

0 day of gestation

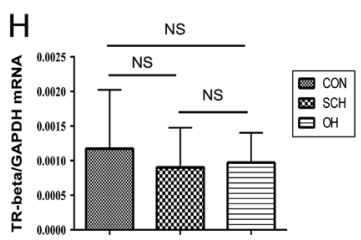

5 days of gestation

Figure 3

TSHR ( $A$ and E), TR- $\alpha 1$ (B and F), TR- $\alpha 2$ ( $C$ and G) and TR- $\beta$ ( $D$ and H) (mean \pm s.D.) mRNA expression in the uterus from the CON, SCH and OH groups at 0 and 5 days of gestation $(* P<0.05)$. NS, non-significant.

pre-receptive (1-3 days after fertilization), receptive (day 4 after fertilization) and non-receptive phases (day 5 after fertilization) $(15,16)$. Embryo implantation can only occur during the receptive phase, and the process cannot be completed in the other two phases.

Thyroid hormones play an important role in embryo implantation and the early stages of development. In this study, we used a model of subclinical hypothyroidism in pregnant rats via the complete surgical removal of the thyroid and subcutaneous injection of $\mathrm{L}_{-} \mathrm{T}_{4}$ (9). The results of serological tests in rat models indicated that this method was feasible and reproducible. The uterine tissues of pregnant rats were collected on E0 and E5, and the placentas and embryos were also collected on E13. We found that on E0 and E5, the weight of the uteri were significantly decreased in the $\mathrm{SCH}$ and $\mathrm{OH}$ groups compared to the controls. On E13, the weight of the placentas and embryos were significantly reduced in $\mathrm{SCH}$ and $\mathrm{OH}$ groups. Moreover, the number of implantation sites in the $\mathrm{SCH}$ and $\mathrm{OH}$ groups were significantly lower than the controls, while embryo absorption rates were significantly increased in the $\mathrm{SCH}$ and $\mathrm{OH}$ groups. These results suggested that hypothyroidism in pregnant rats, even mild hypothyroidism, had adverse effects on pregnancy outcomes.

The thyroid hormone receptor (TR) hypotype, TR $\alpha$ and $\operatorname{TR} \beta$, bind to $\mathrm{T} 3$ and regulate $\mathrm{TSH}$-related gene expression. Previous studies have reported that TR and the TSH receptor (TSHR) play a vital role during the implantation window and show a wide range of
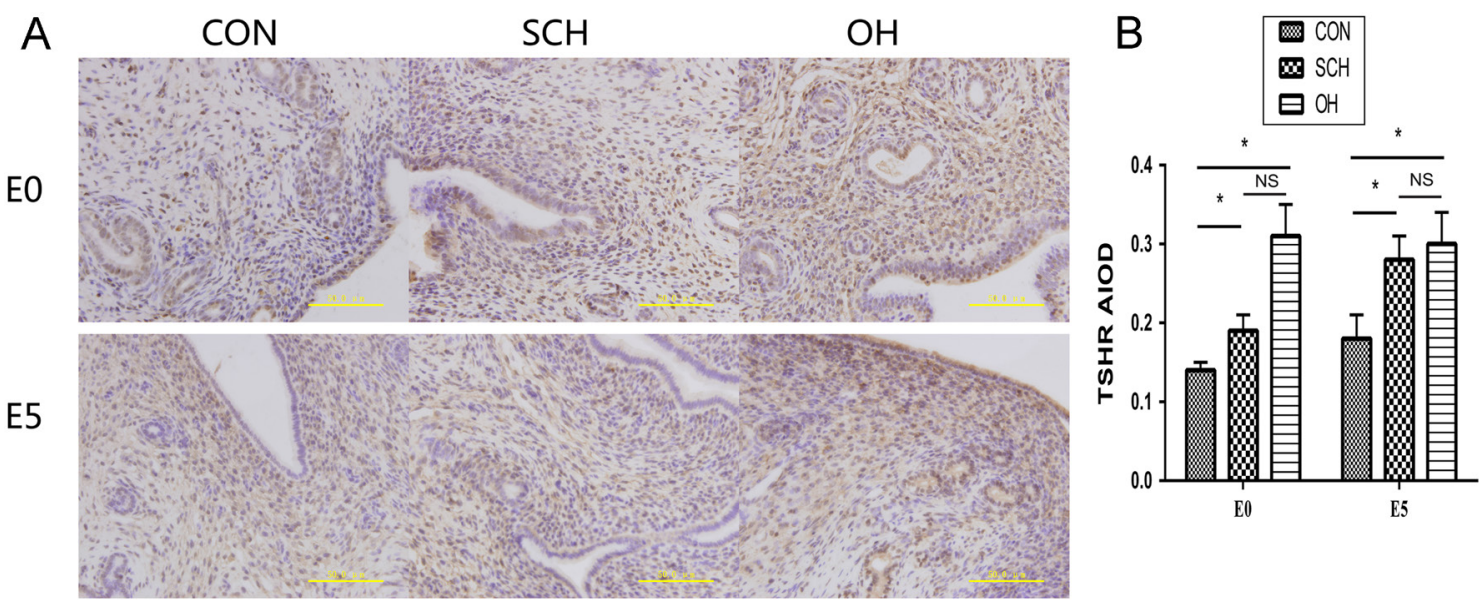

\section{Figure 4}

TSHR immunohistochemical staining of uteri from the $\mathrm{CON}, \mathrm{SCH}$ and $\mathrm{OH}$ groups at 0 and 5 days of gestation. (A) Immunohistochemical images of TSHR expression (streptavidin-biotin-peroxidase, Harris hematoxylin, scale bar $=50 \mu \mathrm{m}$ ). (B) Increased AOID levels of TSHR in uteri from the SCH and OH groups compared with the CON group at 0 and 5 days of gestation $(* P<0.05)$. NS, non-significant.

https://ec.bioscientifica.com

https://doi.org/10.1530/EC-19-0185 (c) 2019 The authors Published by Bioscientifica Ltd

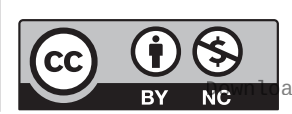

This work is licensed under a Creative Commons Attribution-NonCommercial 4.0 International License. ded from Bioscientifica.com at $04 / 26 / 2023$ 11:54:26AM 

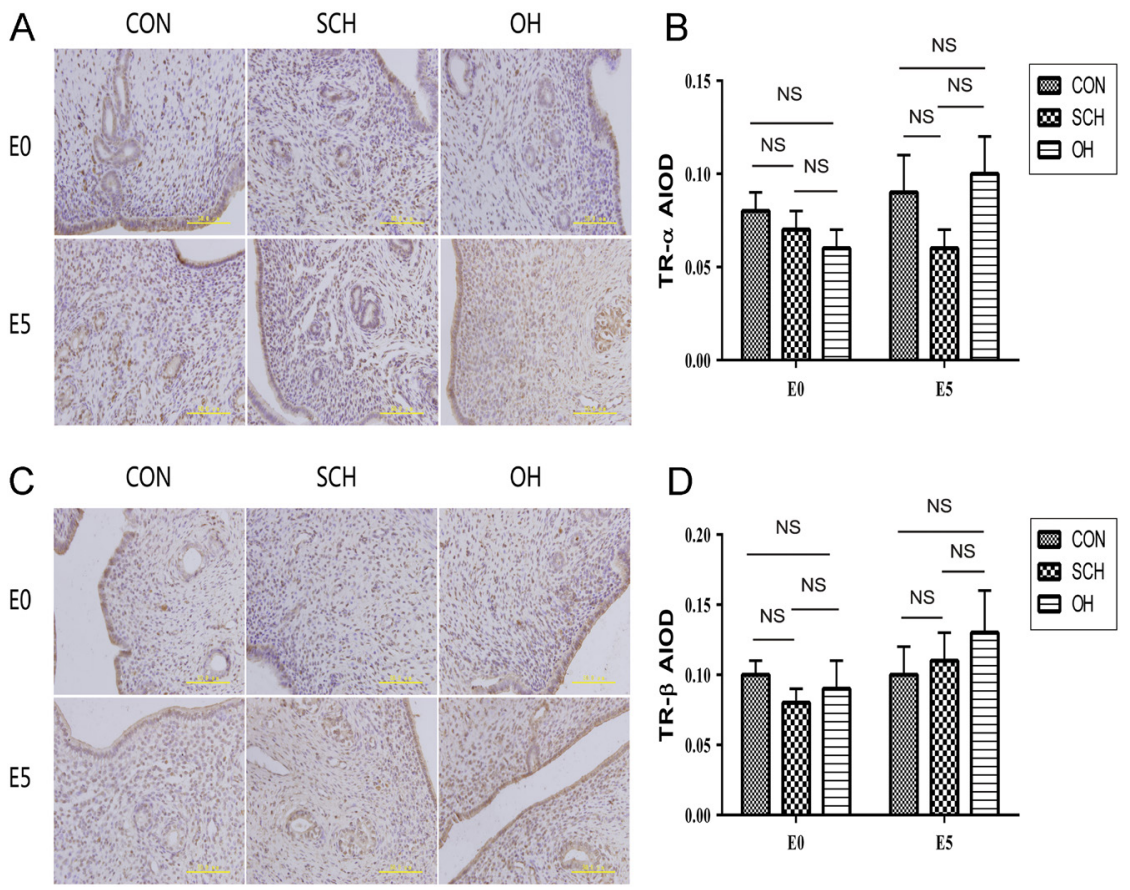

\section{Figure 5}

TR- $\alpha$, and TR- $\beta$ immunohistochemical staining of uteri from the $\mathrm{CON}, \mathrm{SCH}$ and $\mathrm{OH}$ groups at 0 and 5 days of gestation. ( $A$ and $C$ )

Immunohistochemical images of TR- $\alpha$ and TR- $\beta$ expression (streptacidin-biotin-peroxidase, Harris hematoxylin, scale bar $=50 \mu \mathrm{m})$. (B and D) AOID evels of TR- $\alpha$ and TR- $\beta$ in uteri from the SCH and $\mathrm{OH}$ groups compared with the $\mathrm{CON}$ group at 0 and 5 days of gestation (no significant difference). NS, non-significant.

expressions in the maternal fetal unit, thus confirming that TH and TSH in the vicinity of the endometrium and fetus may directly or indirectly regulate the process of embryo implantation $(17,18)$. Stewart et al. suggested that abnormal menstruation and increased miscarriage are likely to be due to the direct effects of TSH on the uterus in women with abnormal thyroid function (19). In this study, we found that the mRNA and AOID levels
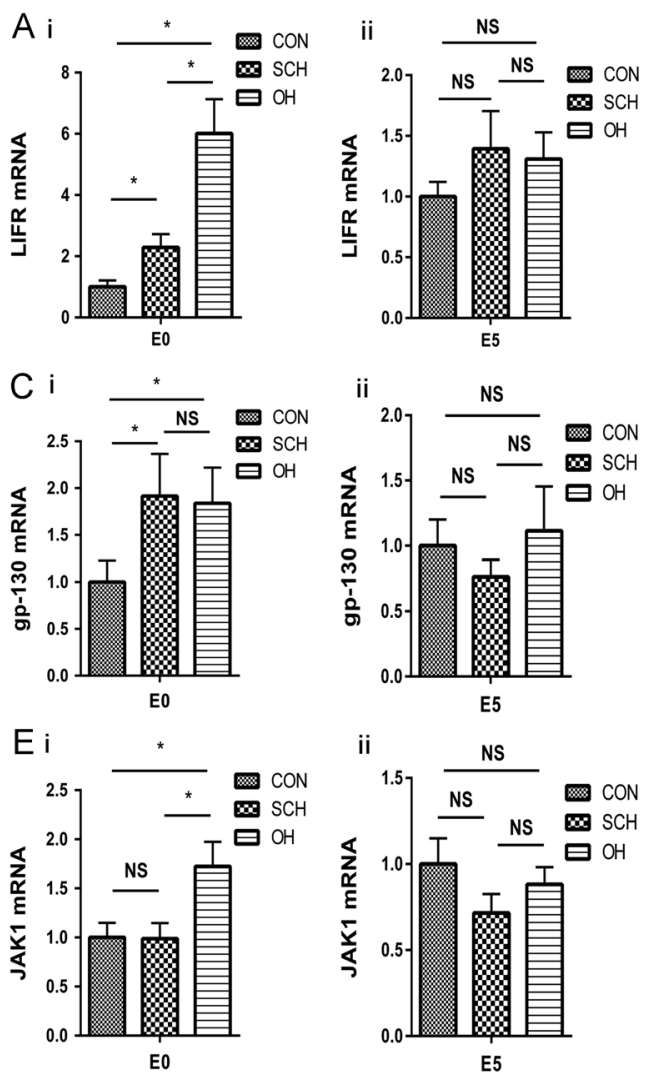
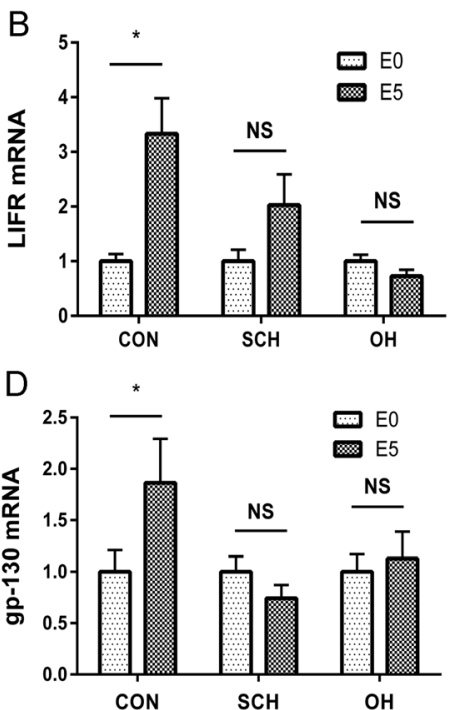

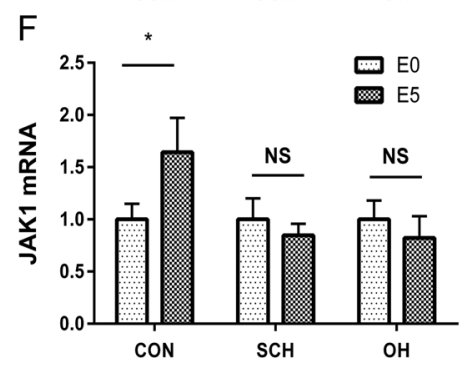

Figure 6

LIFR (A and B), gp130 (C and D) and JAK1 (E and F) (mean \pm s.D.) mRNA expression in uteri from the $\mathrm{CON}, \mathrm{SCH}$ and $\mathrm{OH}$ groups at 0 and 5 days of gestation $\left({ }^{*} P<0.05\right)$. NS, non-significant. https://ec.bioscientifica.com https://doi.org/10.1530/EC-19-0185 (c) 2019 The authors Published by Bioscientifica Ltd

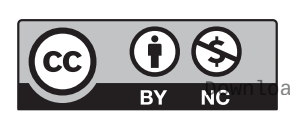

This work is licensed under a Creative Commons Attribution-NonCommercial 4.0 International License. ded from Bioscientifica.com at $04 / 26 / 2023$ 11:54:26AM 
A

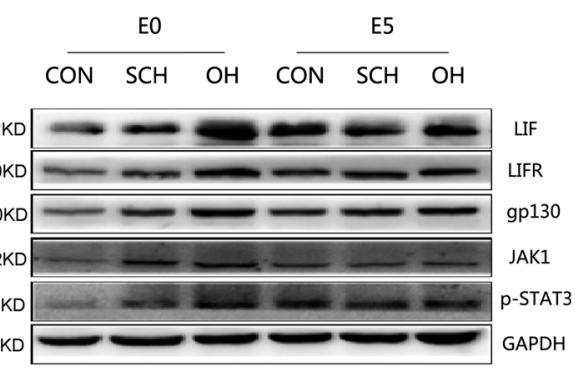

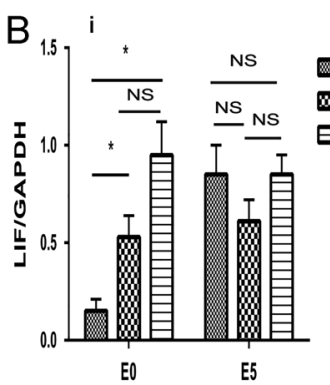
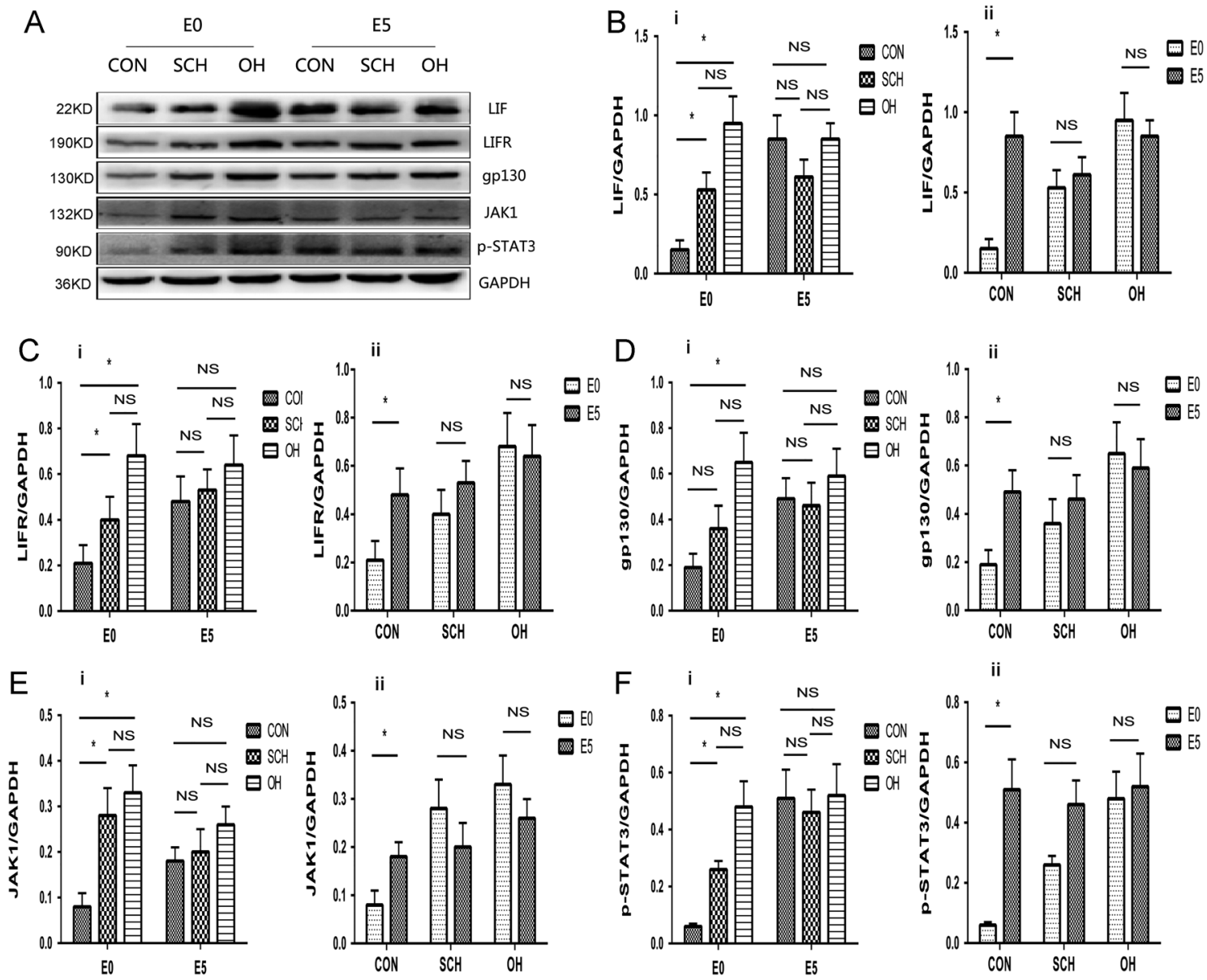

\section{Figure 7}

(A) Protein expression of LIF, LIFR, gp130, JAK1 and p-STAT3. LIF (B), LIFR (C), gp130 (D), JAK1 (E) and p-STAT3 (F) protein levels in uteri from the CON, SCH and $\mathrm{OH}$ groups at $\mathrm{O}$ and 5 days of gestation $(* P<0.05)$. NS, non-significant.

of TSHR in the $\mathrm{SCH}$ and $\mathrm{OH}$ groups were significantly higher than those in the controls, while TR- $\alpha$ and TR- $\beta$ showed no significant difference when compared across the three groups. This is consistent with the results of Stewart et al. (19).

LIF is a vital cytokine expressed in human endometrial cells and is known to play a role in the process of implantation $(20,21)$. Many studies have confirmed that the abnormal expression of LIF is related to abnormal embryo implantation $(22,23)$. LIF combines with the LIF receptor complex (composed of LIFR and gp130) distributed on the surface of luminal epithelial cells to form a stable LIF-LIFR-gp130 complex (24). This complex can activate JAK1 enzymes, resulting in the phosphorylation of the intracellular domain, results in the recruitment and phosphorylation of the latent signal transducer and activator of transcription 3 (STAT3). In a number of animal studies, disruption of the JAK-STAT pathway, using a variety of models, ultimately resulted in the failure of blastocyst implantation $(25,26)$.

It has been demonstrated that TSH can stimulate LIF expression in the thyroid of monkeys (27). An in vitro study measured the effects of TSH on the LIF signaling pathway in cultured samples of endometrium (17) and showed that TSH dramatically increased the expression of LIF in stromal cells. Moreover, TSH can also promote the mRNA expression of LIFR, which indicated the participation of TSH in the mediation of LIF signaling (17). In this study, we examined the expression of the LIF-STAT3 pathway in each of our treatment groups. Our results showed that elevated serum TSH upregulated expression of the LIF-STAT3 pathway prior to the uterine receptivity phase, thus promoting the upregulation of LIF-STAT3 in the $\mathrm{CON}$ group, but not in the $\mathrm{SCH}$ and $\mathrm{OH}$ groups during the implantation window. Thus, an abnormal LIF/STAT3 pathway in uterine tissue may be related to abnormal

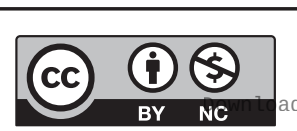

This work is licensed under a Creative Commons Attribution-NonCommercial 4.0 International License. ded from Bioscientifica.com at 04/26/2023 11:54:26AM via free access 
patterns of embryo implantation in rats in the $\mathrm{OH}$ and $\mathrm{SCH}$ groups. This supports the hypothesis that elevated TSH may affect the LIF/STAT3 pathway, rendering the blastocyst and uterus in a 'non-synchronous' state, and eventually leading to implantation failure (28).

In conclusion, high levels of TSH exerted influence over the LIF/STAT3 signaling pathway and ultimately led to implantation failure. This mechanism may participate in adverse pregnancy outcomes in women with clinical and subclinical thyroid dysfunction.

\section{Declaration of interest}

The authors declare that there is no conflict of interest that could be perceived as prejudicing the impartiality of the research reported.

\section{Funding}

This work was supported by the Chinese National Natural Science Foundation (81570709, 81700688). The Foundation of Key Laboratory in Department of Education of Liaoning Province Government in China (LZ2014035).

\section{References}

1 Shan ZY, Chen YY, Teng WP, Yu XH, Li CY, Zhou WW, Gao B, Zhou JR, Ding B, Ma Y, et al. A study for maternal thyroid hormone deficiency during the first half of pregnancy in China. European Journal of Clinical Investigation 200939 37-42. (https://doi. org/10.1111/j.1365-2362.2008.02055.x)

2 Blatt AJ, Nakamoto JM \& Kaufman HW. National status of testing for hypothyroidism during pregnancy and postpartum. Journal of Clinical Endocrinology and Metabolism 201297 777-784. (https://doi. org/10.1210/jc.2011-2038)

3 Benhadi N, Wiersinga WM, Reitsma JB, Vrijkotte TG \& Bonsel GJ. Higher maternal TSH levels in pregnancy are associated with increased risk for miscarriage, fetal or neonatal death. European Journal of Endocrinology 2009160 985-991. (https://doi. org/10.1530/EJE-08-0953)

4 Wang S, Teng WP, Li JX, Wang WW \& Shan ZY. Effects of maternal subclinical hypothyroidism on obstetrical outcomes during early pregnancy. Journal of Endocrinological Investigation 201235 322-325. (https://doi.org/10.3275/7772)

5 Negro R, Schwartz A, Gismondi R, Tinelli A, Mangieri T \& StagnaroGreen A. Increased pregnancy loss rate in thyroid antibody negative women with TSH levels between 2.5 and 5.0 in the first trimester of pregnancy. Journal of Clinical Endocrinology and Metabolism 201095 E44-E48. (https://doi.org/10.1210/jc.2010-0340)

6 Suman P, Malhotra SS \& Gupta SK. LIF-STAT signaling and trophoblast biology. JAK-STAT 20132 e25155. (https://doi.org/10.4161/jkst.25155)

7 Tapia A, Salamonsen LA, Manuelpillai U \& Dimitriadis E. Leukemia inhibitory factor promotes human first trimester extravillous trophoblast adhesion to extracellular matrix and secretion of tissue inhibitor of metalloproteinases-1 and -2. Human Reproduction 2008 23 1724-1732. (https://doi.org/10.1093/humrep/den121)

8 Makrigiannakis A, Zoumakis E, Kalantaridou S, Coutifaris C, Margioris AN, Coukos G, Rice KC, Gravanis A \& Chrousos GP. Corticotropin-releasing hormone promotes blastocyst implantation and early maternal tolerance. Nature Immunology 20012 1018-1024. (https://doi.org/10.1038/ni719)
9 Zhang Y, Fan Y, Yu X, Wang X, Bao S, Li J, Fan C, Shan Z \& Teng W. Maternal subclinical hypothyroidism impairs neurodevelopment in rat offspring by inhibiting the CREB signaling pathway. Molecular Neurobiology 201552 432-441. (https://doi.org/10.1007/s12035-0148855-x)

10 Franchi A, Zaret J, Zhang X, Bocca S \& Oehninger S. Expression of immunomodulatory genes, their protein products and specific ligands/receptors during the window of implantation in the human endometrium. Molecular Human Reproduction 200814 413-421. (https://doi.org/10.1093/molehr/gan029)

11 Altmae S, Reimand J, Hovatta O, Zhang P, Kere J, Laisk T, Saare M, Peters M, Vilo J, Stavreus-Evers A, et al. Research resource: interactome of human embryo implantation: identification of gene expression pathways, regulation, and integrated regulatory networks. Molecular Endocrinology 201226 203-217. (https://doi.org/10.1210/me.2011-1196)

12 Koot YE \& Macklon NS. Embryo implantation: biology, evaluation, and enhancement. Current Opinion in Obstetrics and Gynecology 2013 25 274-279. (https://doi.org/10.1097/GCO.0b013e3283630d94)

13 Cuman C, Menkhorst EM, Rombauts LJ, Holden S, Webster D, Bilandzic M, Osianlis T \& Dimitriadis E. Preimplantation human blastocysts release factors that differentially alter human endometrial epithelial cell adhesion and gene expression relative to IVF success. Human Reproduction 201328 1161-1171. (https://doi.org/10.1093/ humrep/det058)

14 Sharkey AM \& Macklon NS. The science of implantation emerges blinking into the light. Reproductive Biomedicine Online 201327 453-460. (https://doi.org/10.1016/j.rbmo.2013.08.005)

15 Dey SK, Lim H, Das SK, Reese J, Paria BC, Daikoku T \& Wang H. Molecular cues to implantation. Endocrine Reviews 200425 341-373. (https://doi.org/10.1210/er.2003-0020)

16 Wang H \& Dey SK. Roadmap to embryo implantation: clues from mouse models. Nature Reviews: Genetics 20067 185-199. (https://doi. org/10.1038/nrg1808)

17 Aghajanova L, Stavreus-Evers A, Lindeberg M, Landgren BM, Sparre LS \& Hovatta O. Thyroid-stimulating hormone receptor and thyroid hormone receptors are involved in human endometrial physiology. Fertility and Sterility 201195 230.e231-237.e232.

18 Evers S. Paracrine interactions of thyroid hormones and thyroid stimulation hormone in the female reproductive tract have an impact on female fertility. Frontiers in Endocrinology 2012350.

19 Stewart EA. Gonadotropins and the uterus: is there a gonadindependent pathway? Journal of the Society for Gynecologic Investigation 20018 319-326.

20 Aghajanova L. Leukemia inhibitory factor and human embryo implantation. Annals of the New York Academy of Sciences 20041034 176-183. (https://doi.org/10.1196/annals.1335.020)

21 Aghajanova L, Stavreus-Evers A, Nikas Y, Hovatta O \& Landgren BM. Coexpression of pinopodes and leukemia inhibitory factor, as well as its receptor, in human endometrium. Fertility and Sterility 200379 (Supplement 1) 808-814. (https://doi.org/10.1016/S00150282(02)04830-6)

22 Subramani E, Madogwe E, Ray CD, Dutta SK, Chakravarty B, Bordignon V, Duggavathi R \& Chaudhury K. Dysregulated leukemia inhibitory factor and its receptor regulated signal transducers and activators of transcription 3 pathway: a possible cause for repeated implantation failure in women with dormant genital tuberculosis? Fertility and Sterility $2016 \mathbf{1 0 5} 1076$. e5-1084.e5. (https://doi. org/10.1016/j.fertnstert.2015.12.015)

23 Yen CF, Liao SK, Huang SJ, Tabak S, Arcuri F, Lee CL, Arici A, Petraglia F, Wang HS \& Kayisli UA. Decreased endometrial expression of leukemia inhibitory factor receptor disrupts the STAT3 signaling in adenomyosis during the implantation window. Reproductive Sciences 201724 1176-1186. (https://doi.org/10.1177/1933719116681515)

24 Rosario GX, Hondo E, Jeong JW, Mutalif R, Ye X, Yee LX \& Stewart CL. The LIF-mediated molecular signature regulating murine https://ec.bioscientifica.com https://doi.org/10.1530/EC-19-0185 (c) 2019 The authors Published by Bioscientifica Ltd

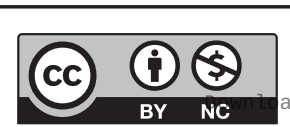

This work is licensed under a Creative Commons Attribution-NonCommercial 4.0 International License. ded from Bioscientifica com at 04/26/2023 11:54:26AM 
embryo implantation. Biology of Reproduction 201491 66. (https:// doi.org/10.1095/biolreprod.114.118513)

25 Lee JH, Kim TH, Oh SJ, Yoo JY, Akira S, Ku BJ, Lydon JP \& Jeong JW. Signal transducer and activator of transcription-3 (Stat3) plays a critical role in implantation via progesterone receptor in uterus. FASEB Journal 201327 2553-2563. (https://doi.org/10.1096/fj.12-225664)

26 Ernst M, Inglese M, Waring P, Campbell IK, Bao S, Clay FJ, Alexander WS, Wicks IP, Tarlinton DM, Novak U, et al. Defective gp130-mediated signal transducer and activator of transcription (STAT) signaling results in degenerative joint disease, gastrointestinal ulceration, and failure of uterine implantation. Journal of
Experimental Medicine 2001194 189-203. (https://doi.org/10.1084/ jem.194.2.189)

27 Ren SG, Seliktar J, Li X, Hershman JM, Braunstein GD \& Melmed S. In vivo and in vitro regulation of thyroid leukemia inhibitory factor (LIF): marker of hypothyroidism. Journal of Clinical Endocrinology and Metabolism 199984 2883-2887. (https://doi.org/10.1210/ jcem.84.8.5918)

28 Rosario GX \& Stewart CL. The multifaceted actions of leukaemia inhibitory factor in mediating uterine receptivity and embryo implantation. American Journal of Reproductive Immunology 201675 246-255. (https://doi.org/10.1111/aji.12474)

Received in final form 30 April 2019

Accepted 7 May 2019
This work is licensed under a Creative Commons Attribution-NonCommercial 4.0 International License. 